\title{
Retraction Note: Slope rainfall environment characteristics based on target tracking algorithm and economic efficiency of green city
}

Yujie Zhan ${ }^{1,2} \cdot$ Xinchun $\mathrm{Li}^{1}$

Published online: 12 November 2021

C) Saudi Society for Geosciences 2021

Retraction Note: Arabian Journal of Geosciences (2021) 14: 1895

https://doi.org/10.1007/s12517-021-08094-z

The Editor-in-Chief and the Publisher have retracted this article because the content of this article is nonsensical. The peer review process was not carried out in accordance with the Publisher's peer review policy. The authors have not responded to correspondence regarding this retraction.

The original article can be found online at https://doi.org/10.1007/ s12517-021-08094-z.

Xinchun Li

doctorzhan2021@126.com

1 China University of Mining Technology, Xuzhou 221116, Jiangsu, China

2 Xuzhou College of Industrial Technology, Xuzhou 221140, Jiangsu, China 